\title{
Effect of Process Parameters on the Formation of Lack of Fusion in Directed Energy Deposition of Ti-6Al-4V Alloy
}

\author{
Desrilia Nursyifaulkhair*, Nokeun Park*,**, Eung Ryul Baek,**,† and Jong-bong Lee*** \\ *School of Materials Science and Engineering, Yeungnam University, Gyeongsan, 38541, Korea \\ **Institute of Materials Technology, Yeungnam University, Gyeongsan, 38541, Korea \\ ***Pohang Institute of Metal Industry Advancement (POMIA), Pohang, 37666, Korea \\ †Corresponding author : erbaek@yu.ac.kr \\ (Received May 8, 2019 ; Revised June 20, 2019 ; Accepted September 10, 2019)
}

\begin{abstract}
The effect of different process parameters on the formation of lack of fusion (LOF) in Ti-6Al-4V alloy fabricated using DED was studied. The specific energy was calculated to evaluate the minimal amount of required energy to avoid LOF. The results showed that a specific energy smaller than $2700 \mathrm{J.g}^{-1}$ led to the formation of LOF; however, a higher specific energy was able to successfully prevent the defect. A smaller amount of specific energy resulted in inadequate heat, which was too low to completely melt the metal powder, and resulted in insufficient penetration depth. Subsequently, LOF was observed between the interface of the deposited layers. Furthermore, a higher powder feed rate had a more significant effect on the formation of LOF than higher laser power.
\end{abstract}

Key Words : Ti-6Al-4V alloy, Directed energy deposition, Powder feed rate, Laser power, Lack of fusion

\section{Introduction}

Lack of fusion (LOF) is identified as an irregular and large porosity with the sharp edges, as a result of incomplete adherence of the melt to the surrounding part 1). The formation of lack of fusion (LOF) in the most utilized titanium alloy, Ti-6Al-4V, can act as a stress concentration $^{2,3)}$, which extremely lowered ultimate tensile strength and elongation ${ }^{3}$. Furthermore, the occurrence of this defect also yielded a large anisotropy in the strength and the elongation of Ti-6Al-4V alloy ${ }^{4,5)}$. In general, the LOF can be found in the products of conventional welding and additive manufacturing (AM). In the conventional welding, the defect generally forms at the interfaces between the filler and the base metal or between the different layers of the filler metal ${ }^{6}$. Similarly, the LOF in the AM occurs at the interfaces of the deposited layers.

The AM is a promising technology to produce nearshape components and reduce materials waste ${ }^{7)}$. This technology generally is distinguished into directed en- ergy deposition (DED) and powder bed fusion (PBF). Compared to PBF, DED has a higher productivity because of its faster process ${ }^{8,9}$. In the DED, there are several process parameters, such as laser power, travel speed, and powder feed rate, which influence the presence of the $\mathrm{LOF}^{10)}$. The layer by layer technique is able to introduce the LOF at the interface of layers, and as a result, it is difficult to produce a fully dense component with the consistent mechanical properties ${ }^{11)}$. Therefore, in this work, we focused on investigating the effect of different DED process parameters on the formation of LOF in Ti-6Al-4V alloy. Furthermore, we also calculated the specific energy from different process conditions during DED of Ti-6Al-4V alloy in this work and the other published papers to confirm the results. Hence, the minimal required specific energy to eliminate the formation of LOF in the DED of Ti-6Al-4V alloy can be obtained.

\section{Experimental Method}

The Ti-6Al-4V AM specimen was manufactured using 

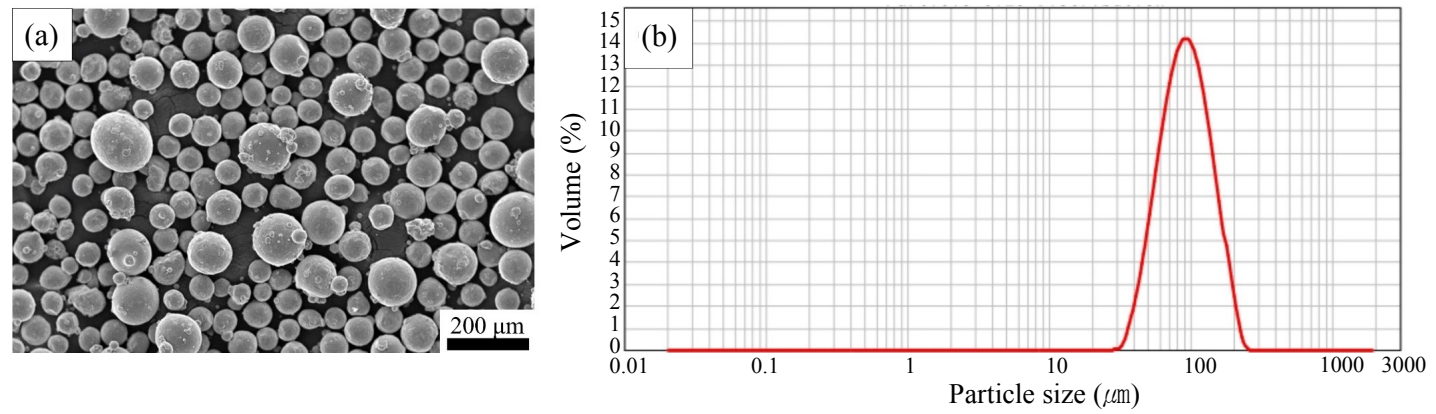

Fig. 1 (a) Ti-6Al-4V powder and (b) size distribution with average size of around $90 \mu \mathrm{m}$

a DED process by depositing the metal powder onto a substrate of the same alloy. The metal powder with the average size of approximately $90 \mu \mathrm{m}$ was produced using plasma atomization method (Fig. 1). During the manufacture, a single mode IPG fiber laser of 700,800 , and $900 \mathrm{~W}$ was utilized with the focal length of $9 \mathrm{~mm}$, the beam diameter of $1 \mathrm{~mm}$ and the zigzag scanning method. Furthermore, the powder feed rate was varied to 3,6 , and $9 \mathrm{~g} \cdot \mathrm{min}^{-1}$. The travel speed was set at $900 \mathrm{~mm} \cdot \mathrm{min}^{-1}$ and the Ar shielding gas was flowed at $3 \mathrm{~L} \cdot \mathrm{min}^{-1}$ to protect melt pool from the contaminant. Table 1 summarizes the process conditions applied in this DED fabrication.

After the manufacture, the specimens were prepared for an optical observation. The specimens were cut in a cross-sectional direction, followed by a grinding using $\mathrm{SiC}$ paper and a mechanical polishing using 1- $\mu \mathrm{m}$ diamond suspension. An optical microscopy (OM) examination was conducted to observe the presence of LOF in the specimens. Furthermore, the specific energies from the process parameters in this work and the other works were measured to find the minimal specific energy for avoiding the LOF. The specific energy $\left(\mathrm{J} \cdot \mathrm{g}^{-1}\right)$ was calculated using these following formulas which were used in the laser cladding process ${ }^{12)}$ :

Table 1 Summary of DED process parameters to build the Ti-6Al-4V alloy in this work

\begin{tabular}{|c|c|c|c|c|}
\hline No. & $\begin{array}{c}\text { Name of } \\
\text { specimen }\end{array}$ & $\begin{array}{c}\text { Laser power } \\
(\mathrm{W})\end{array}$ & $\begin{array}{c}\text { Powder feed rate } \\
\left(\mathrm{g} \cdot \mathrm{min}^{-1}\right)\end{array}$ & $\begin{array}{c}\text { Travel speed } \\
\left(\mathrm{mm} \cdot \mathrm{min}^{-1}\right.\end{array}$ \\
\hline 1. & $700-3$ & 700 & 3 & 900 \\
\hline 2. & $700-6$ & 700 & 6 & 900 \\
\hline 3. & $700-9$ & 700 & 9 & 900 \\
\hline 4. & $800-3$ & 800 & 3 & 900 \\
\hline 5. & $800-6$ & 800 & 6 & 900 \\
\hline 6. & $800-9$ & 800 & 9 & 900 \\
\hline 7. & $900-3$ & 900 & 3 & 900 \\
\hline 8. & $900-6$ & 900 & 6 & 900 \\
\hline 9. & $900-9$ & 900 & 9 & 900 \\
\hline
\end{tabular}

$$
\begin{aligned}
& \text { Mass feed per unit length }=\frac{m}{v} \\
& \text { Linear energy input }=\frac{\alpha P}{v} \\
& \text { Specific energy }=\frac{\text { Linear energy input }}{\text { Mass feed per unit length }}
\end{aligned}
$$

From the Eq. (1)-(2), m, v, $\alpha$, and P are the powder feed rate $\left(\mathrm{g} \cdot \mathrm{min}^{-1}\right)$, the travel speed $\left(\mathrm{mm} \cdot \mathrm{min}^{-1}\right)$, the laser absorption coefficient of $0.27^{13)}$, and the laser power (W), respectively. The specific energy is the linear energy input divided by the mass feed per unit length, as described in the Eq. (3). Moreover, the value of specific energy was used to evaluate the maximal melt pool temperature $\left(\mathrm{T}_{3}\right)$ using the Eq. (4):

$$
T_{3}=\frac{\frac{Q}{m}-c_{1}\left(T_{2}-T_{1}\right)-L}{c_{2}}+T_{2}
$$

where $\frac{Q}{m}$ is the specific energy $\left(\mathrm{J} \cdot \mathrm{g}^{-1}\right), \mathrm{c}_{1}$ and $\mathrm{c}_{2}$ are the specific heat capacities of Ti-6Al-4V alloy at room temperature and melting temperature $\left(\mathrm{J} \cdot \mathrm{g}^{-1} \cdot \mathrm{K}^{-1}\right)$, respectively. Moreover, $T_{1}$ and $T_{2}$ are the initial temperature of Ti-6Al-4V powder (assuming at room temperature or $298 \mathrm{~K}$ ) and the melting temperature of Ti-6Al-4V (1877 $\mathrm{K}^{14)}$ ), respectively, and $\mathrm{L}$ is the latent heat of Ti-6Al-4V alloy $\left(\mathrm{J} \mathrm{g}^{-1}\right)$. The maximal melt pool temperature is the peak temperature arising at the center of the heated melt pool $^{15)}$. This temperature is relatively higher than the melting temperature $\left(\mathrm{T}_{2}\right)$ of Ti-6Al-4V. It can affect the temperature of previous layer to obtain the melting point or even higher, thus making a good fusion between the melt pool and the previous layer. On the other hand, the minimal temperature at the rear boundary of the melt pool was assumed to be at the melting temperature. Hence, the mean melt pool temperature was estimated by calculating the average of the maximal melt pool temperature and the melting temperature of Ti-6Al-4V alloy ${ }^{15)}$.

\section{Results}

Fig. 2a shows the overview of an as-built DED Ti- 


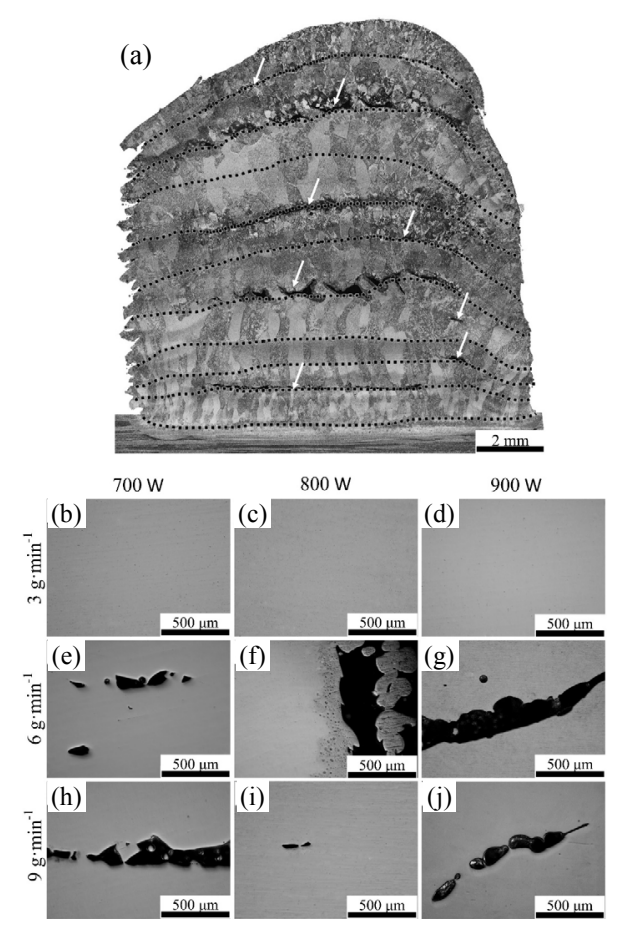

Fig. 2 (a) As-built condition of Ti-6Al-4V in the specimen 900-9 representing the formation of LOF between the layers, designated by the white arrows. (b-j) OM images of all specimens showing the LOF in the specimens with the feed rates of 6 and $9 \mathrm{~g} \cdot \mathrm{min}^{-1}$

$6 \mathrm{Al}-4 \mathrm{~V}$ specimen which represents the presence of LOF between the interface of deposited layers. Furthermore, the OM images of all specimens with the different process parameters are shown in Fig. 2b. It was observed that the LOF was not formed in the specimens of 700-3, 800-3 and 900-3, however, the other specimens with the higher powder feed rates suffered from the defect. It implies that an increase in laser power did not affect extensively on avoiding the formation of LOF in this experiment. On the other hand, a higher powder feed rate contributed significantly to the formation of the defect. This might indicate that a higher volume of the metal powder cannot be fully melted to obtain a good interlayer bonding.

The values of the specific energy, the mean melt pool temperature, and the formation of LOF for the specimens are listed in Table 2. It shows the specific energies of $1260-2430 \mathrm{~J} \cdot \mathrm{g}^{-1}$ and the mean melt pool temperatures of $1915-2525 \mathrm{~K}$ resulted in the formation of the defect. On the other hand, at the specific energies of 3780-4320 $\mathrm{J} \cdot \mathrm{g}^{-1}$ with the mean melt pool temperatures of 3229$3510 \mathrm{~K}$, the presence of LOF was not found in the specimens. Moreover, it shows a critical range of specific energy between 2430 and $3780 \mathrm{~J} \cdot \mathrm{g}^{-1}$ where the LOF can still be formed.

\section{Discussion}

The LOF was formed in the specimens because of a smaller amount of specific energy applied during the DED process ${ }^{16)}$. It caused the metal powder incompletely melted owing to lower melt pool temperature, and this condition led to an insufficient penetration depth to the previous layer ${ }^{4,17)}$, consequently, introducing an interlayer porosity at the interface of deposited layers. Therefore, it is important to yield an adequately mean pool temperature for fully melting the powder and achieving an appropriate penetration depth with the pre-existing layer or substrate. Subsequently, the lack of fusion between the deposited layers can be eliminated.

Furthermore, the specific energies from the DED process conditions of Ti-6Al-4V in the other works ${ }^{11,18,20)}$ were also calculated to confirm the minimal specific energy to avoid the LOF. In the Table 3, it is noticed that the LOF was formed in the specimen at the specific energy of $2661 \mathrm{~J} \cdot \mathrm{g}^{-1}$ with the melt pool temperature of $2646 \mathrm{~K}$. Hence, it indicates that the LOF can still be formed in the critical specific energy range of 2430-

Table 2 Results of the specific energy and the mean melt pool temperature calculations, and the presence of LOF in this work

\begin{tabular}{|c|c|c|c|c|c|c|}
\hline No & $\begin{array}{l}\text { Name of } \\
\text { specimen }\end{array}$ & $\begin{array}{l}\text { Specific energy } \\
\left(\mathrm{J} \cdot \mathrm{g}^{-1}\right)\end{array}$ & $\begin{array}{l}\text { Initial temperature of } \\
\text { Ti-6Al-4V powder }(\mathrm{K})\end{array}$ & $\begin{array}{l}\text { Melting temperature of } \\
\text { Ti-6Al-4V } \mathrm{V}^{14)}(\mathrm{K})\end{array}$ & $\begin{array}{l}\text { Mean melt pool } \\
\text { temperature }(\mathrm{K})\end{array}$ & $\begin{array}{l}\text { Presence of } \\
\text { LOF }\end{array}$ \\
\hline 1. & $700-3$ & 3780 & 298 & 1877 & 3229 & No \\
\hline 2. & $700-6$ & 1890 & 298 & 1877 & 2243 & Yes \\
\hline 3. & $700-9$ & 1260 & 298 & 1877 & 1915 & Yes \\
\hline 4. & $800-3$ & 4320 & 298 & 1877 & 3510 & No \\
\hline 5. & $800-6$ & 2160 & 298 & 1877 & 2384 & Yes \\
\hline 6. & $800-9$ & 1440 & 298 & 1877 & 2009 & Yes \\
\hline 7. & 900-3 & 4860 & 298 & 1877 & 3792 & No \\
\hline 8. & $900-6$ & 2430 & 298 & 1877 & 2525 & Yes \\
\hline 9. & $900-9$ & 1620 & 298 & 1877 & 2103 & Yes \\
\hline
\end{tabular}


Table 3 The process parameters and the formation of LOF in DED of Ti-6Al-4V from the other works ${ }^{11,18,20)}$ to estimate the specific energies and the mean melt pool temperatures

\begin{tabular}{|c|c|c|c|c|c|c|c|c|c|}
\hline Name & $\begin{array}{l}\text { Laser } \\
\text { power } \\
\text { (W) }\end{array}$ & $\begin{array}{c}\text { Travel speed } \\
\left(\mathrm{mm} \cdot \mathrm{min}^{-1}\right)\end{array}$ & $\begin{array}{l}\text { Feed rate } \\
\left(\mathrm{g} \cdot \mathrm{min}^{-1}\right)\end{array}$ & $\begin{array}{c}\text { Specific } \\
\text { energy }\left(J \cdot g^{-1}\right)\end{array}$ & $\begin{array}{c}\text { Initial temperature } \\
\text { of Ti-6Al-4V } \\
\text { powder }(\mathrm{K})\end{array}$ & 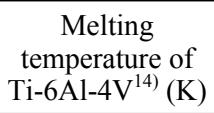 & \begin{tabular}{|c|} 
Mean melt pool \\
temperature \\
$(\mathrm{K})$
\end{tabular} & $\begin{array}{c}\text { Presence of } \\
\text { LOF }\end{array}$ & Ref. \\
\hline R 1 & 2000 & 636 & 8.0 & 4050 & 298 & 1877 & 3370 & No & 11) \\
\hline R 2 & 250 & 408 & 2.8 & 1473 & 298 & 1877 & 2026 & Yes & 18) \\
\hline R 3 & 250 & 510 & 2.8 & 1473 & 298 & 1877 & 2026 & Yes & 18) \\
\hline R 4 & 300 & 408 & 2.8 & 1767 & 298 & 1877 & 2179 & Yes & 18) \\
\hline R 5 & 400 & 635 & 2.4 & 2700 & 298 & 1877 & 2666 & No & 19) \\
\hline R 6 & 1150 & 800 & 7.0 & 2661 & 298 & 1877 & 2646 & Yes & 20) \\
\hline R 7 & 1265 & 800 & 7.0 & 2928 & 298 & 1877 & 2784 & No & 20) \\
\hline R 8 & 1410 & 800 & 6.5 & 3514 & 298 & 1877 & 3090 & No & 20) \\
\hline R 9 & 1440 & 685 & 15.5 & 1505 & 298 & 1877 & 2043 & Yes & 20) \\
\hline
\end{tabular}

$3780 \mathrm{~J} \cdot \mathrm{g}^{-1}$. Meanwhile, at the greater specific energy, $2700 \mathrm{~J}^{-1} \mathrm{~g}^{-1}$, the defect was not formed in the DED Ti$6 \mathrm{Al}-4 \mathrm{~V}$.

The relationship between the specific2043 energy, the mean melt pool temperature and the formation of LOF are shown in Fig. 3. The critical specific energy of LOF formation in this work ranged between 2430 and 3780 $\mathrm{J} \mathrm{g}^{-1}$ (Fig. 3a), thus the minimal specific energy to utterly avoid the defect was $3780 \mathrm{~J} \cdot \mathrm{g}^{-1}$. However, after confirming the results with the specific energies calculated from the process parameters in the other works, the crit-

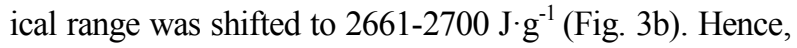
the minimal specific energy to successfully prevent the formation of LOF was $2700 \mathrm{~J} \cdot \mathrm{g}^{-1}$ with the mean melt pool temperature of $2666 \mathrm{~K}$.

Furthermore, in the Fig. 4, it can also be noticed that the combination of a relatively high linear energy input and a lower mass feed per unit length would minimize the probability of LOF formation. Linear energy input was calculated by dividing the absorbed laser power with the travel speed, as described in the Eq. (2). Meanwhile, the mass feed per unit length was obtained by dividing the powder feed rate with the travel speed (Eq. (3)). Since

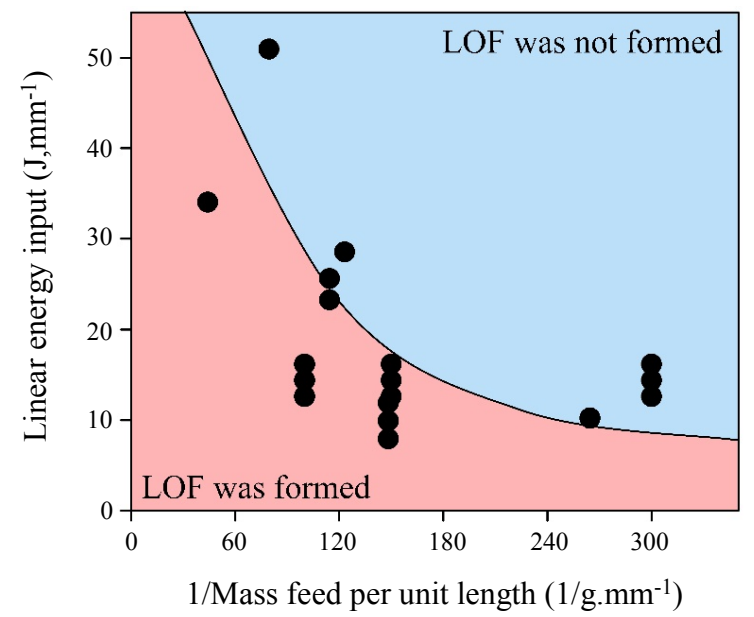

Fig. 4 Influence of mass feed per unit length and linear energy input on the formation of LOF

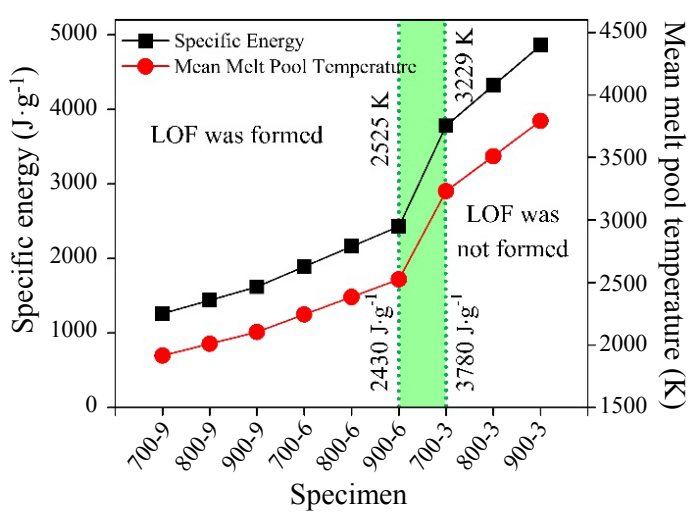

(a)

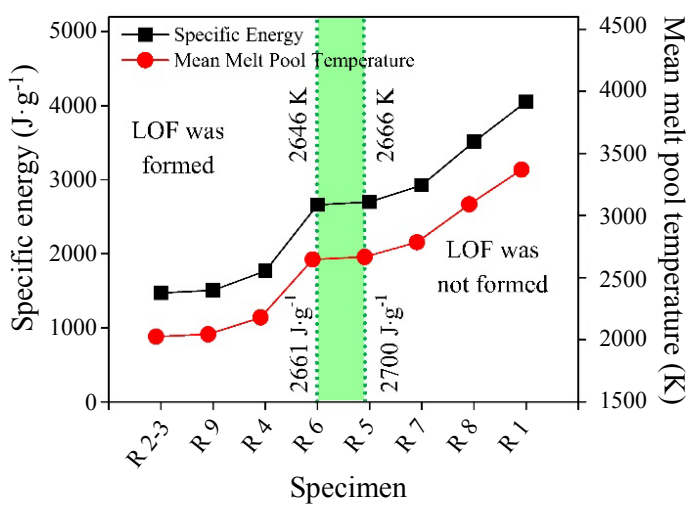

(b)

Fig. 3 Dependence of the LOF formation on the specific energy and the mean melt pool temperature according to the process conditions in (a) this work and (b) the other works ${ }^{11,18,20)}$. The green area in graphs indicates the critical range in which the LOF can be formed 
the travel speed was a constant value, the linear energy input was more influenced by the laser power (Eq. 2), and the mass feed per unit length was more affected by the powder feed rate (Eq. 1). Therefore, the process condition of a higher laser power and a lower powder feed rate should be considered to obtain a proper specific energy, and thus, eliminating the formation of LOF.

\section{Conclusion}

The effect of process parameters on the formation of LOF in the Ti-6Al-4V using DED has been successfully investigated. From the current study, the conclusions are as follows:

1) In this work, the powder feed rate was more critical on the formation of LOF, rather than the laser power.

2) The insufficient specific energy was confirmed as the cause of the formation of LOF in the DED Ti-6Al$4 \mathrm{~V}$ alloy.

3) The critical specific energy was ranged between 2430 and $3780 \mathrm{~J} \cdot \mathrm{g}^{-1}$ in this work, in which the LOF probably can be formed. However, after calculating the specific energy from the various process parameters in the other works, the critical range was shifted to 2661 and $2700 \mathrm{~J} \cdot \mathrm{g}^{-1}$.

\section{Acknowledgement}

This study was supported by the Yeungnam University research grant 2018 .

ORCID: Desrilia Nursyifaulkhair: https://orcid.org/0000-0002-9883-784X ORCID: Nokeun Park: https://orcid.org/0000-0002-7863-1457 ORCID: Eung Ryul Baek: http://orcid.org/0000-0002-1705-342X

\section{References}

1. S. Coeck, M. Bisht, J. Plas, and F. Verbist, Prediction of lack of fusion porosity in selective laser melting based on melt pool monitoring data, Addit. Manuf. 25 (2019) 347-356. https://doi.org/10.1016/j.addma.2018.11.015

2. B. Zhang and Y. Li, Q. Bai, Defect Formation Mechanisms in Selective Laser Melting, A Review, Chinese J. Mech. Eng. 30 (2017) 515-527. https://doi.org/10.1007/s10033-017-0121-5

3. P. Åkerfeldt, M.L. Antti and R. Pederson, Influence of microstructure on mechanical properties of laser metal wire-deposited Ti-6Al-4V, Mater. Sci. Eng. A. 674 (2016) 428-437.

https://doi.org/10.1016/j.msea.2016.07.038

4. H. Gong, K. Rafi, H. Gu, T. Starr and B. Stucker, Analysis of defect generation in Ti-6Al-4V parts made using powder bed fusion additive manufacturing processes,
Addit. Manuf. 1 (2014) 87-98.

https://doi.org/10.1016/j.addma.2014.08.002

5. P.A. Kobryn and S.L. Semiatin, Mechanical Properties of Laser-Deposited Ti-6Al-4V, Solid Free. Fabr. Proc. (2001) 179-186.

6. D. Radaj, Fatigue strength for infinite life of welded joints in structural steel, Des. Anal. Fatigue Resist. Welded Struct. 2 (2010) 36-65.

https://doi.org/10.1533/9781845698751.36

7. A. A. Antonysamy and J. Meyer, P. B. Prangnell, Effect of build geometry on the $\beta$-grain structure and texture in additive manufacture of Ti6Al4V by selective electron beam melting, Mater. Charact. 84 (2013) 153-168. https://doi.org/10.1016/j.matchar.2013.07.012

8. S. Kim and C. Chun, Trend of DED type additive manufacturing technology for titanium, J. Weld. Join. 35 (2017) 23-28. https://doi.org/10.5781/JWJ.2017.35.4.4

9. J. G. Byun and S, M. Cho, Trend of Metal 3D Printing by Welding, J. Weld. Join. 34 (2016) 1-8. https://doi.org/10.5781/JWJ.2016.34.4.1

10. W. J. Sames, F. A. List, S. Pannala, R. R. Dehoff, S. S. and Babu, The metallurgy and processing science of metal additive manufacturing, Int. Mater. Rev. 61 (2016) 315-360.

https://doi.org/10.1080/09506608.2015.1116649

11. B. E. Carroll, T. A. Palmer and A. M. Beese, Anisotropic tensile behavior of Ti-6Al-4V components fabricated with directed energy deposition additive manufacturing, Acta Mater. 87 (2015) 309-320. https://doi.org/10.1016/j.actamat.2014.12.054

12. D. M. Goodarzi, J. Pekkarinen and A. Salminen, Effect of process parameters in laser cladding on substrate melted areas and the substrate melted shape, J. Laser Appl. 27 (2015) S29201. https://doi.org/10.2351/1.4906376

13. H. Zamani, J. Hermani, B. Sonderegger and C. Sommitsch, 3D simulation and process optimization of laser assisted milling of Ti6Al4V, Procedia CIRP. 8 (2013) $75-80$.

https://doi.org/10.1016/j.procir.2013.06.068

14. R. Ramakrishnaiah and A. Abdullah, Preliminary fabrication and characterization of electron beam melted Ti-6Al-4V customized dental implant, Saudi J. Biol. Sci. 24 (2017) 787-796. https://doi.org/10.1016/j.sjbs.2016.05.001

15. Andrew J. Pinkerton and Lin Li, An analytical model of energy distribution in laser direct metal deposition, Proc. Inst. Mech. Eng. Part B J. Eng. Manuf. 218 (2004) 363-374. https://doi.org/10.1243/095440504323055498.

16. A. J. Pinkerton, Laser direct metal deposition: Theory and applications in manufacturing and maintenance, $A d v$. Laser Mater. Process. Technol. Res. Appl. (2010) 461-491. https://doi.org/10.1533/9781845699819.6.461 
17. T. Vilaro, C. Colin, J.D. Bartout, As-fabricated and heattreated microstructures of the Ti-6Al-4V alloy processed by selective laser melting, Metall. Mater. Trans. A Phys. Metall. Mater. Sci. 42 (2011) 3190-3199. https://doi.org/10.1007/s11661-011-0731-y

18. P. A. Kobryn, E. H. Moore and S. L. Semiatin, The effect of laser power and traverse speed on microstructure, porosity, and build height in laser-deposited Ti-6Al-4V, Scr. Mater. 43 (2000) 299-305.

https://doi.org/10.1016/S1359-6462(00)00408-5
19. A. W. Prabhu, T. Vincent, A. Chaudhary, W. Zhang and S. S. Babu, Effect of microstructure and defects on fatigue behaviour of directed energy deposited Ti-6Al-4V, Sci. Technol. Weld. Join. 20 (2015) 659-669. https://doi.org/10.1179/1362171815Y.0000000050

20. C. Qiu, G. A. Ravi, C. Dance, A. Ranson, S. Dilworth, M.M. Attallah, Fabrication of large Ti-6Al-4V structures by direct laser deposition, J. Alloys Compd. 629 (2015) 351-361.

https://doi.org/10.1016/j.jallcom.2014.12.234 